\title{
Effects of macroalgal identity on epifaunal assemblages: native species versus the invasive species Sargassum muticum
}

\author{
Ignacio Gestoso $\cdot$ Celia Olabarria $\cdot$ Jesús S. Troncoso
}

Received: 24 December 2010/Revised: 25 March 2011/Accepted: 6 April 2011/Published online: 5 May 2011

(C) Springer-Verlag and AWI 2011

\begin{abstract}
Seaweeds are a refuge from stressful conditions associated with life on rocky intertidal shores, and there is evidence that different macrophytes support different assemblages of mobile epifauna. Introduction of nonindigenous macroalgae may have a great impact on associated epifaunal assemblages and ecosystem processes in coastal areas. Previous studies have reported conflicting evidences for the ability of epifauna to colonize nonindigenous species. Here, we analyzed epifaunal assemblages associated with three species of macroalgae that are very abundant on intertidal shores along the Galician coast: the two native species Bifurcaria bifurcata and Saccorhiza polyschides and the invasive species Sargassum muticum. We collected samples of each species from three different sites at three different times to test whether variability of epifaunal assemblages was consistent over space and time. Epifaunal assemblages differed between the three macroalgae. Results suggested that stability and morphology of habitat played an important role in shaping the structure of epifaunal assemblages. This study also showed that the invasive $S$. muticum offered a suitable habitat for many invertebrates.
\end{abstract}

Keywords Epifaunal assemblages - Macroalgae · Sargassum muticum · Morphology · Epiphytes ·

Galician coast

Communicated by H.-D. Franke.

I. Gestoso $(\bowtie) \cdot$ C. Olabarria $\cdot$ J. S. Troncoso

Departamento de Ecología y Biología Animal,

Universidad de Vigo, 36310 Vigo, Spain

e-mail: ignaciogestoso@uvigo.es

\section{Introduction}

Intertidal rocky shores on temperate latitudes are often dominated by macroalgae that harbor epifaunal assemblages of associated epibiota, i.e., epifauna and epiphytic algae (Schmidt and Scheibling 2006). In particular, epifaunal assemblages are very influenced by marine macroalgae that exist on the coast, because many invertebrates use macroalgae as a refuge from physical stress, protection from predators, and many of them are herbivores that consume epiphytic algae or the host plant itself (Duffy 1990; Bell 1991; Viejo 1999). There is evidence that different macrophytes support different assemblages of mobile epifauna (Cacabelos et al. 2010 and references therein), and this may be due to several biological factors such as life cycles, algal structure (sensu McCoy and Bell 1991; Gee and Warwick 1994), presence of algal epiphytes (Dawes et al. 2000), habitat complexity (Buschbaum et al. 2006; Schreider et al. 2003), chemical defences (Steinberg et al. 1998), or physical factors (e.g., wave exposure or tidal height) (Chemello and Milazzo 2002; Schreider et al. 2003). Behavioral choices of animals may also account for patterns of distribution, with larger abundance of species in their preferred host habitats (Chapman 2000).

Currently, most ecosystems are affected by an increasing rate of biological invasions that may have strong ecological impacts on resident assemblages (Vitousek et al. 1997; Piazzi et al. 2001; Ross et al. 2004). Together with climate change, non-indigenous macroalgae are becoming one of the most important threats to marine biodiversity (Stachowicz et al. 2002), and changes associated with these introductions may have a great impact on associated epifaunal assemblages and ecosystem processes in coastal areas (Jones et al. 1997; Crooks 2002; Schmidt and Scheibling 2006). The magnitude of this effect will depend 
in part on the ability of epiphytic organisms and free-living epifauna to colonize non-indigenous species (Wikström and Kautsky 2004).

Previous studies have reported conflicting evidences for the ability of epifauna to colonize non-indigenous species. Some studies showed no differences between epifaunal assemblages associated with native and invasive macroalgae (e.g. Viejo 1999; Parker et al. 2001; Edgar and Klumpp 2003), whereas other works found relevant differences (Wernberg et al. 2004; Vázquez-Luis et al. 2008; Prado and Thibaut 2008). In general, most marine invertebrates are associated with multiple macroalgal families as habitats (Hay and Fenical 1988) in contrast with, for example, most species of terrestrial herbivorous insects that show habitat specialization (Fox and Morrow 1981). However, selection of host macroalgae by marine invertebrate is largely dependent upon the identity of the host species (Wernberg et al. 2004; Wikström and Kautsky 2004; Bates 2009).

Sargassum muticum is an invasive species that since 1986 (see Pérez-Cirera et al. 1989) has successfully colonized the shallow subtidal and the low intertidal shores of the Galician coast (northwestern Spain). There, it coexists on exposed and semi-exposed shores with native brown seaweeds such as Bifurcaria bifurcata and Saccorhiza polyschides, forming mixed stands. Due to intrinsic differences between macroalgae (i.e. structural complexity, phenology, morphology, chemical composition, epiphyte load), we could expect differences in epifaunal assemblages associated.

In this study, purely mensurative, the main aim was to compare the epifaunal assemblages associated with three different macroalgae, the invasive species $S$. muticum and the native species $B$. bifurcata and $S$. polyschides. In addition, we wanted to know whether variability of epifaunal assemblages associated with the three macroalgae was consistent over space and time.

\section{Materials and methods}

Study area and sampling design

Sites were located in the lower intertidal zone $(0.4-0.8 \mathrm{~m}$ above the lowest astronomical tide) on the eastern side of two rias, Ria de Aldan $\left(42^{\circ} 20^{\prime} \mathrm{N} ; 8^{\circ} 51^{\prime} \mathrm{W}\right)$ and Ria de Vigo $\left(42^{\circ} 10^{\prime} \mathrm{N} ; 8^{\circ} 51^{\prime} \mathrm{W}\right)$, located in the southern region of the Galician coast, NW Spain (see Gestoso et al. 2010 for detailed description of area). We randomly chose three sites from a pool of available sites with slightly different wave exposure, and dominated by the three macroalgae forming mixed stands. In each site, we randomly collected five replicates of each macroalga, B. bifurcata, S. polyschides, and $S$. muticum. Each replicate was carefully placed into a plastic bag and taken to the laboratory for further sorting. Using this procedure, we were able to sample motile organisms closely associated with the host macroalga, e.g., gastropods and amphipods. All samples were preserved with $70 \%$ ethanol. Each site was sampled in March, April, and July 2006, the period of greatest cover of the three seaweeds.

\section{Laboratory analysis}

In the laboratory, the seaweeds were vigorously washed in a bucket containing freshwater and then sieved through $0.5-\mathrm{mm}$ mesh to recover mobile macroinvertebrates. We also scrutinized the entire thalli of macroalgae to find the epibionts attached to them. Then, all organisms collected were identified to the lowest possible taxonomic level using dissecting and light microscopes, counted and placed in $70 \%$ ethanol. Epiphytic algae were removed from macroalgae, and both macroalgae and epiphytes were dried at $60^{\circ} \mathrm{C}$ for $72 \mathrm{~h}$ and weighed. Animal abundance was quantified and standardized to numbers per $10 \mathrm{~g}$ alga dry weight (without algal epiphytes). In the case of fragmented animals (such as polychaetes), only heads were counted. Animals included in this study were within a size range from roughly 0.3 to $5 \mathrm{~cm}$.

\section{Data analysis}

Changes in number of species (S), number of individuals $(\mathrm{N})$ and diversity $\left(\mathrm{H}^{\prime}\right.$, Shannon-Wiener index) were analyzed using orthogonal three-factor analyses of variance (ANOVA). The ANOVA model included Time (3 levels; March, April, and July) and Site (3 levels) as random factors, and Habitat (3 levels: B. bifurcata, S. polyschides, and $S$. muticum) as a fixed factor. When significant differences between main factors or their interactions were found, Student-Newman-Keuls (SNK) tests were used as a posteriori comparison. The homogeneity of variances was examined using Cochran's C-test, and data were transformed when necessary to remove heteroscedasticity (Underwood 1997). In order to investigate the relationship between epiphytic biomass and epifaunal assemblages, Kendall's coefficient of rank correlation $(\tau)$ was calculated for each univariate parameter $\left(\mathrm{N}, \mathrm{S}, \mathrm{H}^{\prime}\right)$ in each macroalga.

Three-factor orthogonal non-parametric multivariate analysis of variance (PERMANOVA) on a Bray-Curtis similarity matrix calculated on square root transformed data was used to test the hypothesis about differences between assemblages associated with the three seaweeds (Anderson 2001). Only significant effects $(P<0.05)$ were further investigated through a series of pairwise comparisons using the appropriate terms in the model. To graphically visualize multivariate patterns in assemblages, non-metric multidimensional scaling (nMDS) was used to produce 
two-dimensional ordination plots. This required plots of the centroids that were calculated from principal coordinates analysis obtained from the full Bray-Curtis dissimilarity matrix among the 45 observations in each habitat (McArdle and Anderson 2001). Euclidean distances were then obtained between each pair of centroids and used as the input matrix for the nMDS. SIMPER analysis (Clarke 1993) was performed to identify the species that mostly contributed to similarity/dissimilarity between the 3 habitats. We obtained the percentage contribution $\left(\delta_{i} \%\right)$ of each taxon to the BrayCurtis dissimilarity between habitats. Species (or taxa) were considered important if their percentage dissimilarity was $\geq 3 \%$ (Benedetti-Cecchi and Chato Osio 2007). The ratio $\delta_{i} / \mathrm{SD}\left(\delta_{i}\right)$ was used to indicate the consistency with which a given taxon contributed to the average dissimilarity in all pairwise comparisons of samples between the two habitats. Values $\geq 1$ indicated a high degree of consistency. All the multivariate analyses were performed using PRIMER software package (Clarke and Gorley 2006).

\section{Results}

Gastropods were the most abundant group in the three habitats accounting for 27 to $45 \%$ of the total abundance
(Fig. 1a). Bivalves were the second more abundant group in $B$. bifurcata (Fig. 1b), whereas isopods and polychaetes were the following more abundant groups associated with $S$. muticum and $S$. polyschides, respectively (Fig. 1c, d). Isopods were the less abundant group associated with $B$. bifurcata and $S$. polyschides, whereas bivalves were the less abundant group associated with $S$. muticum.

\section{Univariate analyses}

Analyses of variance revealed no significant differences between habitats for number of species, whereas number of individuals and diversity changed across habitats, but inconsistently over time and site (i.e. significant interaction Habitat $\times$ Time $\times$ Site; Table 1$)$. In general, number of individuals was larger in $S$. polyschides than in the other two macroalgae, with a peak of abundance than varied temporally in each site (Fig. 2a). Whereas in S. muticum, abundance peaked in July, in all sites (SNK tests, $P<0.05$ ), abundance in B. bifurcata did not show significant temporal variability (Table 1; Fig. 2a). Diversity showed a significant tendency to increase in July for epifaunal assemblages associated with $S$. muticum and $S$. polyschides (SNK test, $P<0.05$ ), but in general B., bifurcata was the most diverse habitat (Fig. 2b).
Fig. 1 Percentage of most abundant groups found in epifaunal assemblages. a Total percentage of main taxa in the three habitats; $\mathbf{b}$ percentage of main taxa associated with Bifurcaria bifurcata; c percentage of main taxa associated with Sargassum muticum; and $\mathbf{d}$ percentage of main taxa associated with Sacchoriza polyschides
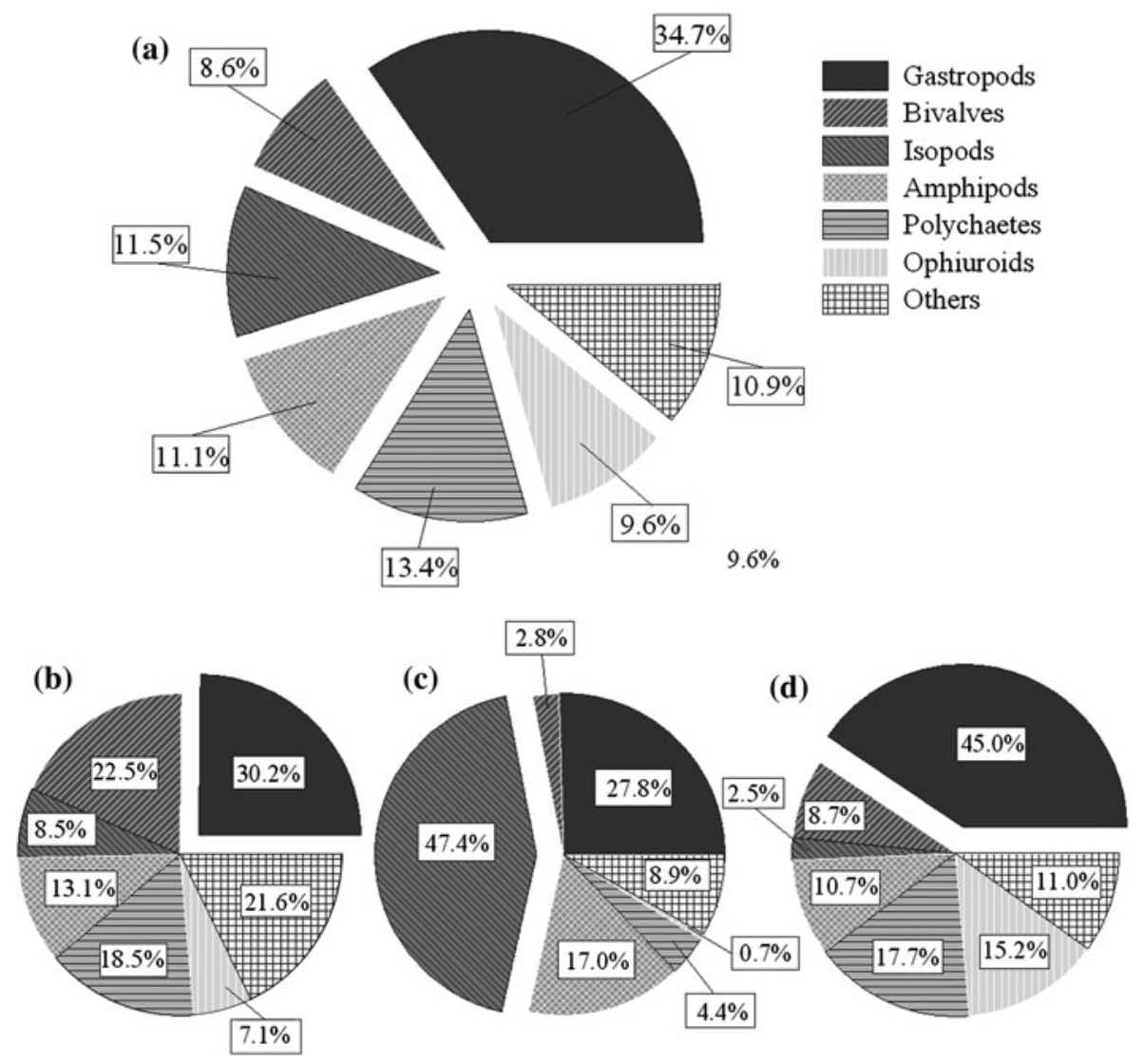
Table 1 Univariate analyses of variance (ANOVA) of number of species (S), number of individuals (N), and Shannon diversity index $\left(\mathrm{H}^{\prime}\right)$ $(n=5)$

\begin{tabular}{|c|c|c|c|c|c|c|c|}
\hline \multirow[t]{2}{*}{ Source } & \multirow[t]{2}{*}{$d f$} & \multicolumn{2}{|l|}{$\mathrm{S}$} & \multicolumn{2}{|l|}{$\mathrm{N}$} & \multicolumn{2}{|l|}{$\mathrm{H}^{\prime}$} \\
\hline & & $F$ & $P$ & $F$ & $P$ & $F$ & $P$ \\
\hline $\mathrm{T}$ & 2 & 0.364 & 0.713 & 6.534 & 0.358 & 1.272 & 0.373 \\
\hline S & 2 & 1.410 & 0.342 & 0.099 & 0.913 & 1.126 & 0.435 \\
\hline $\mathrm{H}$ & 2 & 0.172 & 0.849 & 0.667 & 0.610 & 0.102 & 0.905 \\
\hline $\mathrm{T} \times \mathrm{S}$ & 4 & 3.141 & 0.079 & 0.604 & 0.671 & 1.358 & 0.329 \\
\hline $\mathrm{T} \times \mathrm{H}$ & 4 & 1.785 & 0.225 & 0.945 & 0.486 & 3.269 & 0.072 \\
\hline $\mathrm{S} \times \mathrm{H}$ & 4 & 1.433 & 0.307 & 1.126 & 0.409 & 1.415 & 0.313 \\
\hline $\mathrm{T} \times \mathrm{S} \times \mathrm{H}$ & 8 & 1.345 & 0.229 & 2.777 & 0.008 & 1.987 & 0.055 \\
\hline Res & 108 & & & & & & \\
\hline Total & 134 & & & & & & \\
\hline Cochran's $C$ test & & \multicolumn{2}{|c|}{$C=0.7170(P<0.01)$} & \multicolumn{2}{|c|}{$C=0.1699(P<0.05)$} & \multicolumn{2}{|c|}{$C=0.1513$ (not significant) } \\
\hline Transformation & & \multicolumn{2}{|l|}{$\operatorname{Ln}(x)$} & \multicolumn{2}{|c|}{$\operatorname{Sqrt}(x+1)$} & \multicolumn{2}{|l|}{ None } \\
\hline
\end{tabular}

Time (3 levels, random, orthogonal), Site (3 levels, fixed orthogonal), and Habitat (3 levels, fixed, orthogonal)

Time $=\mathrm{T}$, Site $=\mathrm{S}$, Habitat $=\mathrm{H}$

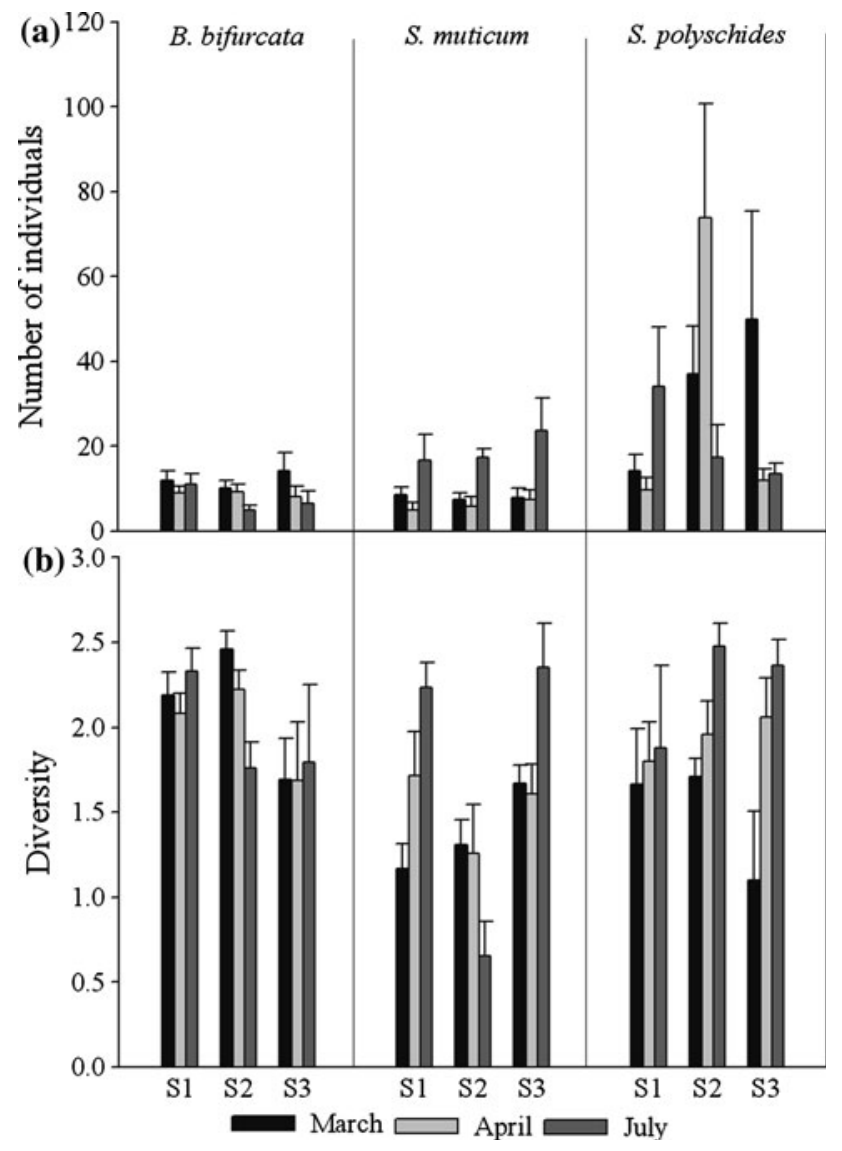

Fig. 2 Mean ( + SE, $n=5)$ of a number of individuals; and b diversity of epifaunal assemblages associated with Bifurcaria bifurcata, Sargassum muticum and Sacchoriza polyschides in March, April, and July in each site. Data were standardized per $10 \mathrm{~g}$ dry weight of alga
Epiphytic biomass varied among habitats, although the greatest biomass was found in S. polyschides (Fig. 3). There was a significant positive correlation between the epiphytic biomass and the number of species, number of individuals and diversity in S. muticum and S. polyschides, although correlation values were low. Correlations were generally higher in $S$. polyschides (number of species, $\tau=0.414$; number of individuals, $\tau=0.333$; diversity, $\tau=0.455$; $P<0.01 ; n=45$ ) than in $S$. muticum (number of species, $\tau=0.239, P<0.05$; number of individuals, $\tau=0.512$, $P<0.01$; diversity, $\tau=0.237, P<0.05 ; n=45$ ).

\section{Multivariate analyses}

There was variation among epifaunal assemblages associated with the three macroalgae, but such variation was not consistent across space and time (i.e., significant interaction Time $\times$ Site $\times$ Habitat; Table 2). In general, epifaunal assemblages differed between the three macroalgae in all sites over time (Fig. 4), although such differences were not significant in only one site during April (pairwise test, $P>0.05$; Table 2). SIMPER analysis (Table 3) showed high average dissimilarities between the three habitats (B. bifurcata and S. muticum $=87.44 ;$ B. bifurcata and $S$. polyschides $=92.19 ; S$. muticum and $S$. polyschides $=$ 95.57). Dynamene bidentata was the species that mostly contributed to dissimilarity between $B$. bifurcata and S. muticum and S. muticum and S. polyschides, whereas Bittium reticulatum was the most important species contributing to dissimilarity between $B$. bifurcata and S. polyschides (Table 3 ). 


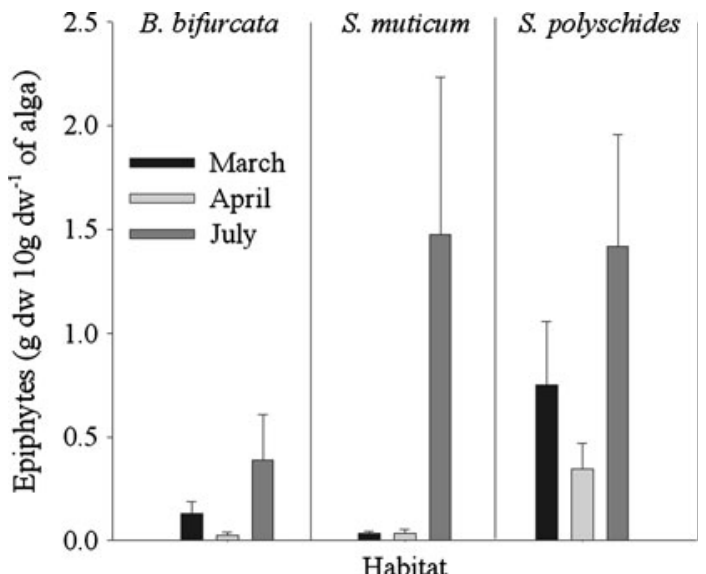

Fig. 3 Mean dry weight of alga (+S.E., $n=15)$ of biomass of epiphytes associated with the three habitats over time. Data were standardized per $10 \mathrm{~g}$ dry weight of alga

Table 2 Non-parametric multivariate analysis of variance (PERMANOVA) examining similarities between epifaunal assemblages $(n=5)$

\begin{tabular}{lrll}
\hline Source & $d f$ & Pseudo-F & $P($ perm $)$ \\
\hline $\mathrm{T}$ & 2 & 2.3208 & 0.003 \\
$\mathrm{~S}$ & 2 & 2.8155 & 0.001 \\
$\mathrm{H}$ & 2 & 3.6431 & 0.001 \\
$\mathrm{~T} \times \mathrm{S}$ & 4 & 2.3420 & 0.001 \\
$\mathrm{~T} \times \mathrm{H}$ & 4 & 2.2785 & 0.001 \\
$\mathrm{~S} \times \mathrm{H}$ & 4 & 1.7521 & 0.004 \\
$\mathrm{~T} \times \mathrm{S} \times \mathrm{H}$ & 8 & 1.5173 & 0.001 \\
Res & 108 & & \\
Total & 134 & & \\
\hline
\end{tabular}

Time (3 levels, random, orthogonal), Site (3 levels, random, orthogonal), and Habitat (3 levels, fixed, orthogonal)

Pairwise tests for pairs of levels of factor Habitat. Only non-significant results are shown: L3 in April: $P$ (perm) $=0.063$

Time $=\mathrm{T}$, Site $=\mathrm{S}$, Habitat $=\mathrm{H}$

\section{Discussion}

In line with our prediction, epifaunal assemblages differed between the three macroalgae. Differences mainly due to changes in abundance of individuals of each species and composition of the main faunistic groups were generally consistent over space and time. Our results are, therefore, in agreement with previous studies that have found differences in composition and structure of epifaunal assemblages associated with native and invasive macroalgae (Wernberg et al. 2004; Vázquez-Luis et al. 2008; Prado and Thibaut 2008).

The total number of individuals and diversity associated with the three macroalgae differed. In general, S. polyschides

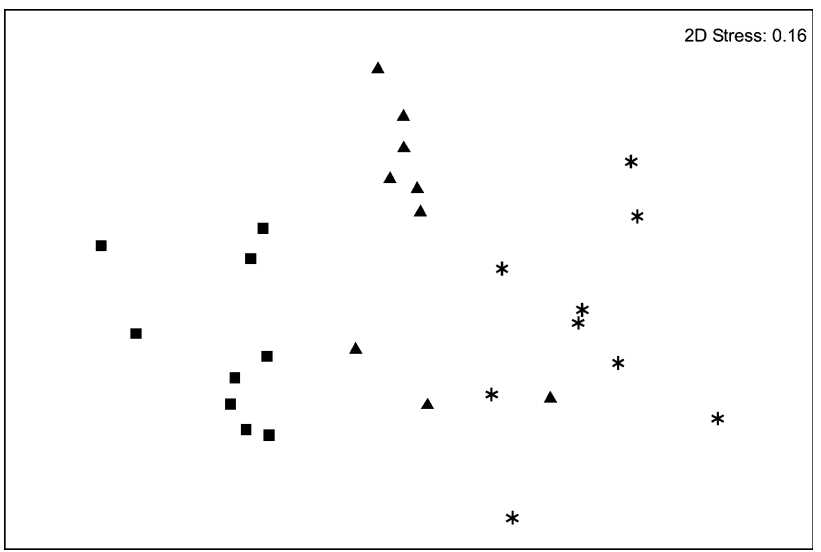

Fig. 4 Non-metric multidimensional scaling (nMDS) for epifaunal assemblages associated with the three macroalgae $(n=5)$. Centroids of Sargassum muticum (asterisk), Bifurcaria bifurcata (filled triangle), and Saccorhiza polyschides (filled square)

Table 3 SIMPER analysis showing the contribution $\left(\bar{\delta}_{i}\right)$ of individual taxa to the average Bray-Curtis dissimilarity between Bifurcaria bifurcata, Sargassum muticum, and Saccorhiza polyschides $(n=45)$

\begin{tabular}{|c|c|c|c|c|c|}
\hline \multirow[t]{2}{*}{ Taxon } & \multicolumn{2}{|c|}{ Average abundance } & \multirow[t]{2}{*}{$\bar{\delta}_{i}$} & \multirow[t]{2}{*}{$\bar{\delta}_{i} \%$} & \multirow[t]{2}{*}{$\bar{\delta}_{i} / \mathrm{SD}\left(\delta_{i}\right)$} \\
\hline & B.bifurcata & S. muticum & & & \\
\hline Dynamene bidentata & 0.62 & 4.52 & 19.85 & 22.70 & 1.13 \\
\hline Mytilus galloprovincialis & 1.09 & 0.20 & 5.67 & 6.49 & 0.68 \\
\hline Bittium reticulatum & 0.92 & 0.49 & 5.36 & 6.13 & 0.79 \\
\hline Cingulopsis fulgida & 0.19 & 0.93 & 4.68 & 5.36 & 0.74 \\
\hline Nematoda & 0.57 & 0.20 & 3.48 & 3.98 & 0.71 \\
\hline Rissoa parva & 0.34 & 0.56 & 3.32 & 3.80 & 0.72 \\
\hline Caprella pernantis & 0.03 & 0.56 & 3.21 & 3.67 & 0.46 \\
\hline \multirow[t]{2}{*}{ Capitellidae } & 0.61 & 0.03 & 3.20 & 3.66 & 0.44 \\
\hline & B.bifurcata & S. polyschides & & & \\
\hline Bittium reticulatum & 0.92 & 8.49 & 9.79 & 10.62 & 0.74 \\
\hline Mytilus galloprovincialis & 1.09 & 1.77 & 6.66 & 7.23 & 0.60 \\
\hline Sabellidae & 0.10 & 3.20 & 6.56 & 7.11 & 0.80 \\
\hline Ophiotrix fragilis & 0.02 & 2.83 & 5.39 & 5.85 & 0.68 \\
\hline Rissoa parva & 0.34 & 1.60 & 5.12 & 5.55 & 0.45 \\
\hline \multirow[t]{2}{*}{ Amphiura securigera } & 0.32 & 1.84 & 4.44 & 4.82 & 0.74 \\
\hline & S. muticum & S. polyschides & & & \\
\hline Dynamene bidentata & 4.52 & 0.04 & 15.48 & 16.20 & 1.00 \\
\hline Bittium reticulatum & 0.49 & 8.49 & 8.83 & 9.24 & 0.65 \\
\hline Sabellidae & 0.05 & 3.20 & 6.43 & 6.73 & 0.78 \\
\hline Rissoa parva & 0.56 & 1.60 & 5.43 & 5.68 & 0.47 \\
\hline Ophiotrix fragilis & 0.01 & 2.83 & 5.31 & 5.56 & 0.66 \\
\hline Mytilus galloprovincialis & 0.20 & 1.77 & 4.87 & 5.09 & 0.46 \\
\hline Cingulopsis fulgida & 0.93 & 0.80 & 3.82 & 4.00 & 0.73 \\
\hline Amphiura securigera & 0.10 & 1.84 & 3.79 & 3.97 & 0.71 \\
\hline
\end{tabular}


had the largest number of individuals, whereas B. bifurcata had the greatest diversity. Several studies have pointed out that number of individuals and identity of species in epifaunal assemblages are related to morphology and/or structural complexity of macroalgae (Taylor and Cole 1994; Wernberg et al. 2004; McDonald and Bingham 2010). Here, the fact that the number of individuals was larger in $S$. polyschides could be in part due to the complex structure of $S$. polyschides holdfast. The holdfast of this species has a bulbous structure with a complex internal channeling system and so considerable intersticial space for epifauna (McKenzie and Moore 1981). In contrast, B. bifurcata and S. muticum have more simple holfasts; the holdfast of B. bifurcata is composed of intertwined rhizoidal growths, whereas $S$. muticum has a disk-shape holdfast (Hiscock 1979; Critchley et al. 1990). Not only number of individuals but also identity of epifaunal species could be influenced by differences in the structure of holdfasts (see Arroyo et al. 2004).

Differences in biomass of epiphytes could also account for patterns of abundance of epifauna. In fact, previous studies have indicated a positive correlation between biomass of epiphytes and free-living epifauna (Worm and Sommer 2000; Parker et al. 2001; Wikström and Kautsky 2004). An increase of epiphyte load might increase food resources or complexity of macroalgal habitat affecting the composition and abundance of epifauna. The trophic role of epiphytes over the increase in structural complexity could be important in increasing diversity of different taxa such as gastropods, isopods, or amphipods (Viejo 1999). For example, the herbivorous isopod $D$. bidentata that was the most abundant species associated with $S$. muticum showed a peak of abundance in July, matching the peak of epiphytic algae. The importance of epiphytic load as food resource for herbivorous and omnivorous taxa has been previously highlighted (Bologna and Heck 1999). In contrast, the role of epiphytes in habitat structure seems to play only a limited role in determining the density of most mobile epifauna, although it appears to be important in augmenting the settlement of bivalves (Bolongna and Heck 1999).

Multivariate analysis indicated that structure of epifaunal assemblages differed between macroalgae. Previous works obtained similar results when comparing how different species of macroalgae modulated abundance, species richness and diversity of assemblages associated (Taylor and Cole 1994; Chemello and Milazzo 2002). In addition, several studies found differences in composition and structure of epifaunal assemblages associated with native and invasive macroalgal species (Wernberg et al. 2004; Wikström and Kautsky 2004; Schmidt and Scheibling 2006; Harries et al. 2007; Vazquez-Luis et al. 2008). Here, native species supported a similar proportion of the most abundant taxa (see Fig. 3), whereas the invasive species supported basically 3 main taxa (i.e. gastropods, isopods and amphipods). Nevertheless, epifaunal assemblages associated with the two native species were more dissimilar than those associated with the native B. bifurcata and the invasive $S$. muticum in terms of species composition and abundance. Thus, other factors rather than the origin of species (i.e. native vs invasive) seemed to play a more important role. For example, the larger abundance of isopods and amphipods in S. muticum might respond to certain mechanism of host selection, because many species of these groups remain in constant contact with surfaces and associate preferentially with microhabitats that closely match their body size (Viejo 1999; Parker et al. 2001). Nevertheless, this assumption has to been taken with caution, because in marine habitats small herbivores tend to be generalists and very few species are host plant specialists (Hay and Steinberg 1992; McDonald and Bingham 2010).

Morphology and complexity of macroalgae might also be important factors in shaping the structure of these assemblages and determining habitat choice (see Schreider et al. 2003; Wernberg et al. 2004; Schmidt and Scheibling 2006; Cacabelos et al. 2010). For example, certain crustaceans are more abundant in branched macroalgae than in macroalgae with a foliose morphology (McDonald and Bingham 2010). B. bifurcata and S. muticum have similar morphology in comparison with $S$. polyschides, and thus, we could expect that epifaunal assemblages associated with these species were more similar. On the other hand, habitat stability (as influenced by habitat longevity) could be also an important factor affecting habitat selection in some crustaceans (Duffy and Hay 1991; Wernberg et al. 2004). In this case, B. bifurcata and S. muticum with monophasic life cycles (Jensen 1974; Britton-Simmons 2004) offered a more stable habitat than $S$. polyschides with a biphasic life cycle (Bartsch et al. 2008).

In summary, epifaunal assemblages varied among the three macroalgae. Nevertheless, assemblages associated with the native $B$. bifurcata and the invasive $S$. muticum were more similar than those associated with $S$. polyschides. These results suggested that stability and morphology of habitat played an important role in shaping the structure of epifaunal assemblages. Results suggest that the impact of $S$. muticum invasion on the epifaunal assemblages depends on the similarities between the invasive and the local seaweeds, but it is also related to the impact of the invasion on the macroalgal assemblages. Here, the invasive S. muticum offered a suitable habitat for many invertebrates especially gastropods and isopods. The consequences of these qualitative and quantitative changes of epifauna are unknown, although they could alter the structure and trophic dynamic of the system since invertebrates inhabiting macroalgae are the prey of omnivorous fishes and decapods (Williams 1992). Nevertheless, the effects of introduction 
of S. muticum on the epifauna may be different among sites, depending on the type of native macroalgae and their abundance.

Acknowledgments This research has been supported by the Spanish Government through the Ministry of Education and Science (PROJECT CGL2005-02269). We are grateful to all colleagues for assistance in the field and Dr. Eva Cacabelos for helping with species identification. We also thank Dr. Rosa Viejo, Dr. Francisco Arenas, and Dr. Brezo Martínez for their comments and suggestions. This work complies with the laws and regulations of the Galician and Spanish Governments.

\section{References}

Anderson MJ (2001) A new method for non-parametric multivariate analysis of variance. Aust Ecol 26:32-46

Arroyo NL, Maldonado M, Pérez-Portela R, Benito J (2004) Distribution patterns of meiofauna associated with a sublittoral Laminaria bed in the Cantabrian Sea (north-eastern Atlantic). Mar Bio 144:231-242

Bartsch I, Wiencke C, Bischof K, Buchholz CM, Buck BH, Eggert A, Feuerpfeil $\mathrm{P}$ et al (2008) The genus Laminaria sensu lato: recent insights and developments. Eur J Phycol 43:1-86

Bates CR (2009) Host taxonomic relatedness and functional-group affiliation as predictors of seaweed-invertebrate epifaunal associations. Mar Ecol Prog Ser 387:125-136

Bell SS (1991) Amphipods are insects equivalents? An alternative view. Ecology 72:350-354

Benedetti-Cecchi L, Chato Osio G (2007) Replication and mitigation of effects of confounding variables in environmental impact assessment: effect of marinas on rocky-shore assemblages. Mar Ecol Prog Ser 334:21-35

Bologna PAX, Heck JrKL (1999) Macrofaunal associations with seagrass epiphytes. Relative importance of trophic and structural characteristics. J Exp Mar Biol Ecol 242:21-39

Britton-Simmons KH (2004) Direct and indirect effects of the introduced alga Sargassum muticum on benthic, subtidal communities of Washington State, USA. Mar Ecol Prog Ser 277:61-78

Buschbaum C, Chapman AS, Saier B (2006) How an introduced seaweed can affect epibiota diversity in different coastal systems. Mar Biol 148:743-754

Cacabelos E, Olabarria C, Incera M, Troncoso JS (2010) Effects of habitat structure and tidal height on epifaunal assemblages associated with macroalgae. Est Coat Shelf Sci 89:43-52

Chapman MG (2000) Poor design of behavioural experiments gets poor results: examples from intertidal habitats. J Exp Mar Biol Ecol 250:77-95

Chemello R, Milazzo M (2002) Effect of algal architecture on associated fauna: some evidence from phytal mollusks. Mar Biol 140:981-990

Clarke KR (1993) Non-parametric multivariate analyses of changes in community. Aust Ecol 18:117-143

Clarke KR, Gorley RN (2006) PRIMER v6: user manual/tutorial. PRIMER-E Ltd. Plymouth Marine Laboratory, UK

Critchley AT, de Visscher PRM, Nienhuis PH (1990) Canopy characteristics of the brown alga Sargassum muticum (Fucales, Phaeophyta) in Lake Grevelingen, southwest Netherlands. Hydrobiologia 204-205:211-217

Crooks JA (2002) Characterizing ecosystem-level consequences of biological invasions: the role of ecosystem engineers. Oikos 97:153-166
Dawes CJ, Teasdale BW, Friedlander M (2000) Cell wall structure of the agarophytes Gracilaria tikvaiae and G. cornea (Rhodophyta) and penetration by the epiphyte Ulva lactuca (Chlorophyta). J Appl Phycol 12:567-575. doi:10.1023/A:1026501613984

Duffy JE (1990) Amphipods on seaweeds: partners or pests? Oecologia 83:267-276

Duffy JE, Hay ME (1991) Food and shelter as determinant of food choice by an herbivorous marine amphipod. Ecology 72:12861298

Edgar G, Klumpp DW (2003) Consistencies over regional scales in assemblages of mobile epifauna associated with natural and artificial plants of different shape. Aq Bot 75:275-291

Fox LR, Morrow PA (1981) Specialization: species property or local phenomenon? Science 211:887-893

Gee JM, Warwick RM (1994) Metazoan community structure in relation to the fractal dimensions of marine macroalgae. Mar Ecol Prog Ser 103:141-150

Gestoso I, Olabarria C, Troncoso JS (2010) Variability of epifaunal assemblages associated with native and invasive macroalgae. Mar Fresh Res 61:724-731

Harries DB, Harrow S, Wilson JR, Mair JM, Donnan DW (2007) The establishment of the invasive alga Sargassum muticum on the west coast of Scotland: a preliminary assessment of community effects. J Mar Biol Ass UK 87:1057-1067

Hay ME, Fenical W (1988) Marine plant-herbivore interactions: the ecology of chemical defense. Annu Rev Ecol Syst 19:111-145

Hay ME, Steinberg PD (1992) The chemical ecology of plantherbivore interactions in marine versus terrestrial communities. In: Rosenthal GA, Berenbaum MR (eds) Herbivores: their interactions with secondary plant metabolites: evolutionary and ecological processes. Academic Press, San Diego, pp 371-413

Hiscock S (1979) A field key to the British brown seaweeds (Phaeophyta). FSC Publications, Shrewsbury, UK

Jensen J (1974) Morphological studies in Cystoseiraceae and Sargassaceae (Phaeophyceae), with special reference to apical organization. Univ Calif Publ Bot 68:1-61

Jones CG, Lawton JH, Shachak M (1997) Positive and negative effects of organisms as physical ecosystem engineers. Ecology 78:1946-1957

McArdle BH, Anderson MJ (2001) Fitting multivariate models to community data: a comment on distance-based redundancy analysis. Ecology 82:290-297

McCoy ED, Bell SS (1991) Habitat structure: the evolution and diversification of a complex topic. In: Bell SS, McCoy ED, Mushinsky HR (eds) Habitat structure the physical arrangement of objects in space. Chapman and Hall, London, pp 3-27

McDonald PS, Bingham BL (2010) Comparing macroalgal food and habitat choice in sympatric, tube-building amphipods, Ampithoe lacertosa and Peramphithoe humeralis. Mar Biol 157:1513-1524

McKenzie JD, Moore PG (1981) The microdistribution of animals associated with the bulbous holdfasts of Saccorhiza polyschides (Phaeophyta). Ophelia 20:201-213

Parker JD, Duffy JE, Orth RJ (2001) Plant species diversity and composition: experimental effects on marine epifaunal assemblages. Mar Ecol Prog Ser 224:55-67

Pérez-Cirera JL, Cremades J, Bárbara I (1989) Precisiones sistemáticas y sinecológicas sobre algunas algas nuevas para Galicia o para las costas atlánticas de la Península Ibérica. An Jard Bot Madrid 46:35-45

Piazzi L, Cecherelli G, Cinelli F (2001) Threat to macroalgal diversity: effects of the introduced green alga Caulerpa racemosa in the Mediterranean. Mar Ecol Prog Ser 210:149-159

Prado P, Thibaut T (2008) Differences between epiphytic assemblages on introduced Caulerpa taxifolia and coexisting eelgrass (Zostera capricorni) in Botany Bay (NSW, Australia). Sci Mar 72:645-654 
Ross DJ, Johnson CR, Hewitt CL, Ruiz GM (2004) Interaction and impacts of two introduced species on a soft-sediment marine assemblage in SE Tasmania. Mar Biol 144:747-756

Schmidt AL, Scheibling RE (2006) A comparison of epifauna and epiphytes on native kelps (Laminaria species) and invasive alga (Codium fragile ssp. tomentosoides) in Nova Scotia, Canada. Bot Mar 49:315-330

Schreider MJ, Glasby TM, Underwood A (2003) Effects of height on the shore and on the shore and complexity of habitat on abundances of amphipods on rocky shores in New South Wales, Australia. J Exp Mar Biol Ecol 293:57-71

Stachowicz JJ, Terwin JR, Whitlatch RB, Osman RW (2002) Linking climate change and biological invasion: ocean warming facilitates non indigenous species invasions. Proc Natl Acad Sci USA 99:15497-15500

Steinberg PD, DeNys R, Kjelleberg S (1998) Chemical inhibition of epibiota by Australian seaweeds. Biofouling 12:227-244

Taylor RB, Cole RG (1994) Mobile epifauna on subtidal brown seaweeds in northeastern New Zealand. Mar Ecol Prog Ser $115: 271-282$

Underwood AJ (1997) Experiments in ecology: their logical design and interpretation using analysis of variance. Cambridge University Press, Cambridge, MA
Vázquez-Luis M, Sanchez-Jerez P, Bayle-Sempere JT (2008) Changes in amphipod (Crustacea) assemblages associated with shallow-water algal habitats invaded by Caulerpa racemosa var. cylindracea in the western Mediterranean Sea. Mar Environ Res 65:416-426

Viejo RM (1999) Mobile epifauna inhabiting the invasive Sargassum muticum and two local seaweeds in northern Spain. Aquat Bot 64:131-149

Vitousek PM, Mooney HA, Lubchenco J, Melillo J (1997) Human Domination of Earth's Ecosystems. Science 277:494-499

Wernberg T, Thomsen MS, Staehr PA, Pedersen MF (2004) Epibiota communities of the introduced and indigenous macroalgal relatives Sargassum muticum and Halidrys siliquosa in Limfjorden (Denmark). Helg Mar Res 58:154-161

Wikström SA, Kautsky L (2004) Invasion of habitat-forming seaweed: effects on associated biota. Biol Inv 6:141-150

Williams GA (1992) Theeffect of predation on the life histories of Littorina obtusata and Littorina mariae. J Mar Biol Assoc UK 72:403-416

Worm B, Sommer U (2000) Rapid direct and indirect effects of a single nutrient pulse in a seaweed-epiphyte-grazer system. Mar Ecol Prog Ser 202:283-288 